\title{
Bidding Strategies in Online Art Auctions with Buyout Prices
}

\author{
Peize Dong ${ }^{1, *}$ \\ ${ }^{1}$ Chongqing Foreign Language school, Chongqing, 404100, China \\ ${ }^{*}$ Corresponding author email: guanghua.ren@gecacdemy.cn
}

\begin{abstract}
Online art auctions with buyout prices are extensively applied as a modified form of art auctions for breaking the limit of fixed time auction ends and combining fixed-price selling with English auctions, while numerous problems exist in the real process of these auctions since reliable information on the bidding strategies is relatively rare. The purpose of this study is to analyze the bidding strategies in online art auctions with different buyout prices. After reviewing the auction theory and preceding studies on online auctions, this research paper builds a game model for online art auctions with fixed, temporary, and permanent buyout prices by expanding Vickery's independent private value model, elaborating on the optimal bidding strategy in each type of situation by comparing bidder's valuation and the buyout price. Furthermore, this paper proposes a threshold value to help a bidder understand his best move by considering if his valuation exceeds the threshold value and thus determining whether to choose the buyout option in an art auction.
\end{abstract}

Keywords: Online art auction, bidding strategy, buyout option, game model

\section{INTRODUCTION}

\subsection{Research Background}

The unprecedented development of modern economics is enabling art auctions to be applied extensively in people's daily life. Influenced by multiple factors such as the increasing number of Internet users, the thriving industry of E-commerce, the modification of online auction platforms, and the high cost of traditional art auctions, online art auctions have become an important medium of art trading, resulting in more diverse enterprises entering the online art auction industry, bringing considerable economic benefit to the society.

Since a full online art auction process would normally take place for several weeks, which could cause customer loss and damage profits, a new form of online art auctions - online art auctions with buyout prices - that combined fixed-price selling and traditional English auctions was created. A buyout price refers to the optimal price at which the seller is willing to sell the auction item immediately as soon as a bidder bids this price. Currently, sellers can adopt this method on plenty of online auction platforms, including eBay,
Yahoo! and Taobao. Buyout prices are introduced to solve two perceived drawbacks of regular online auctions: Waiting time and price uncertainty, and they have been justified by appeal to impatience or risk aversion $[1,2]$. There are three major types of online art auctions with buyout prices - online art auctions with fixed, temporary, and permanent buyout prices. Online art auctions with fixed buyout prices are basically consistent with fixed-price selling, in which the seller sells the item during a specific period of time at a specific price. In online art auctions with temporary buyout prices, the first participant has two options. He can choose either to bid or to end the auction with the buyout price. If he chooses to bid, the buyout option will automatically disappear, the participants who come later will only have one option left, which is to bid like in a regular English auction. In this case, the first participant would not only have a privilege, but a dilemma, because after the auction becomes a regular English auction, it is possible that the final price might be lower or higher than the buyout price. In online art auctions with permanent buyout prices, on the other hand, the buyout option is available during the whole auctioning process. While the price ascends, anyone could win the object with the buyout price at any time before the end of the auction. The final price would not go higher than the buyout price. 
Online art auctions are not simple combinations of traditional art auctions and the Internet. Instead, this new medium not only keeps the features of both but also has unique advantages in its transaction pattern and product variety. The regular process of an online auction is shown in Figure 1.

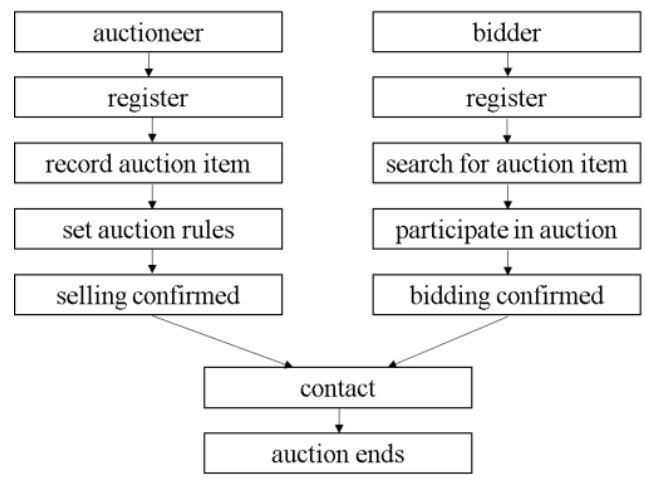

Figure 1. Online auction process

The flexibility of online art auctions enables them to break the limit of time and space. More potential participators would be attracted because, in online art auctions, bidders do not have to be in a specific place at a specific time. At the same time, auctioneers would benefit as well for the fact that they could save the cost for site preparation. A common misconception of online art auctions would be that they exist solely for elites with extravagant tastes that no common people can afford. However, unlike traditional art auctions, online art auctions are accessible for most internet users since artwork at all price levels, from low-cost handicrafts to famous paintings, are for sale in them. From the appearance of the first online auction site, eBay, in 1995 to the present-day skyrocketing online auction market, the platforms have managed to offer bidders information of auction items, bidding progress, and methods of payment. Data released by qianzhan.com in September 2018 shows that the transaction volume of the Chinese auction market had reached 700 billion in 2017 . Moreover, the China Association of Auctioneers (CAA) released a set of data showing that the number of online auctions had increased by $39.4 \%$, and the number of auctions in total by $137.5 \%$ [3].

Although the thriving online auction industry is such a hot topic currently, until now, this industry has only developed for approximately 20 years, and relevant laws, regulations, and auction mechanisms are incomplete. Numerous problems exist in the actual process of online art auctions. For example, information asymmetry and insufficiency would cause the bidders to be irrational, and the winner's curse occurs frequently among inexperienced bidders who would be highly likely to over-valuate on works of art. Therefore, it is essential to study the bidding strategies in online art auctions is essential to help buyers bid rationally.

\subsection{Research Purpose}

Under the current circumstance that online art auctions are increasingly applied, bidders gradually started to realize the fact that they could be better off through more bidding experience, and appropriate bidding strategies enable bidders with greater efficiency to have a larger opportunity to win. As an essential type of management activity, online bidding is used in a large number of security sales, mining right transactions, and raw material transactions, thus being attached great importance to by the researchers. However, the development of online art auctions is still in the early stage, and studies associated with this area are limited, especially studies concerned with bidding strategies in the emerging forms of modified online art auctions.

Considering that bidding strategies are closely related to buyers' economic benefit and efficiency of the auctioning process, this research paper will focus on the question: what are the optimal bidding strategies in online art auctions with different buyout prices? This research can help customers grasp how the above-mentioned types of modified online art auctions work and how to get the optimal bidding strategies in each of them. With the results of this research, auctioneers can better understand customers' bidding strategies and thus develop more appropriate auction mechanisms and more rational bidding mechanisms in order to enhance efficiency.

Preceding researches on both traditional and online auctions have established a firm foundation for this study. In the light of the fact that most studies on online auctions are extensions of those on traditional auctions, the following part will review the general development of the auction theory and then elaborate on the current research status of online auctions and online auctions with buyout prices.

\section{LITERATURE REVIEW}

\subsection{Auction Theory}

The academic researches on auctions began with Vickrey's independent private value model (IPV model) in 1961 and the revenue equivalence theorem. Subsequently, some improvements were made to the drawbacks of the independent private value model and revenue equivalence theorem. However, a limited number of studies at home and abroad involved empirical research.

Friedman's paper published in 1956 and Vickrey's in 1961 laid the foundation of the auction theory. Both scholars have studied auctions from the perspective of bidders' optimal strategy, which fully shows that bidding strategies are an essential element of the auction theory. Friedman proposed the earliest bidding strategy model 
based on the independent private value model, in which customers have private information and independent valuation [4]. Vickrey analyzed the optimal bidding strategies of customers in four common auction types based on the independent private value model [5]. In 1962, Vickrey found that those common auction methods will produce the same expected return under the given conditions, which is the well-known revenue equivalence theorem [6]. However, Vickrey's revenue equivalence theorem is limited to the independent private value model, which is too ideal to happen in real life. Thus, many scholars later expanded the range of former theories by widening the original hypothesis. Some scholars tried to replace the revenue equivalence theorem with the convergence analysis of income. Kremer proved that the first-price sealed-bid auction, second-price sealed-bid auction, and the English auction converge to the expected revenue of goods under the setting of certain public goods in common value in the late 1990s [7]. In 2002, Bali and Jackson proved that under the assumption of common value and private value, all symmetric mechanisms will gradually converge to the same income, which is equal to the expected value of maximum utility of goods [8]. Some scholars broke the convention and used non-traditional research methods concerning the former topic. Leszczyc studied the behavior theory of auction from the perspective of psychology [9]. Milgrom and Weber studied the optimal bidding strategy of customers in four common auction types according to the calculation of expected utility in the affiliated value model (AV Model), which is the milestone for later studies on customer bidding strategies by quantitative analysis [10]. Wilcox also proved through data that the repeated bidding behavior of customers is inverse proportional to the bidding experience of customers [11]. The richer the bidding experience of a bidder, the less repeated bidding behavior would appear. Customers are more likely to have repeated bidding behavior during the early bidding stages.

\subsection{Online auctions}

Moreover, multiple studies associated with online auction bidding behaviors and strategies were conducted. In 2000, Engelbrecht-wiggans explained why actual bidding behaviors are different from theoretical explanations. He believed that it is difficult to take all the changing factors of the actual situation into account in a theoretical research [12]. In the same year, Bapna classified the customers participating in online auctions into three kinds: Evaluators, Participators, and Opportunists, and pointed out that the optimal bidding strategies of different types of customers are different [13]. Moreover, if the time cost is considered, the benefits obtained by different categories of customers will also vary drastically. Bapna's paper summarized the common bidding strategies on online auction sites, including late bidding (sniping), incremental bidding, unmasking, shill bidding, and proxy bidding. Then, he used game theory to prove that in fixed deadline online auctions, the dominant strategy would be late bidding. Ward and Clark complemented Bapna's study by taking eBay.com as the research target, and through multiple experiments, they found that the expected return obtained by adopting the late bidding strategy, or sniping, is lower than the expected profit obtained by adopting the early bidding strategy, or proxy bidding, while the expected return obtained by adopting the repeated bidding strategy is lower than that obtained by adopting the late bidding strategy [14].

\subsection{Online Auctions with Buyout Prices}

With the growing maturity of information, technology, and online auction operations, online English auctions were also modified into their innovative forms. Online English auctions with buyout prices offer the advantage of low opportunity cost and have attracted more and more auctioneers and bidders. Many scholars and experts have studied on topics related to auctions with buyout prices. Lucking-Reiley reviewed online auctions in 2000, mentioning the application of auctions with buyout prices [15]. One year later, Budish and Takeyama approved the online English auctions with buyout prices for the first time. They asserted that when the seller sets an appropriate buyout price, the seller will get the same income as a regular English auction if encountering buyers that are risk-neutral and will get a higher income than a regular English auction if encountering buyers that are risk-averse [2]. In 2004, Wang et al. proposed a buyout model and proved that in an auction with a buyout price, if the participation cost of a bidder is high, his expected utility would be higher than that in other types of auctions. According to the theoretical prediction, sellers would prefer to use English auctions with buyout prices when the number of potential bidders is small. Then, they collected data on eBay and established a model to test their prediction [16]. Caldentey and Vulcano established a model to study the optimal price of two-way auctions by assuming that the arrival of participants follows the Poisson distribution and the utility function of participants has the exponential attenuation effect [17]. Durham et al. provided empirical proof of the effect of buyout prices by conducting an experiment in which 138 pieces of American silver dollars were auctioned, and 41 of them were marked with buyout options with an average price of $\$ 10.27$, and the average price of the rest was $\$ 9.56$. Among the 41 buyout price auctions, $58 \%$ ended at the buyout price, and the average ending price was $\$ 10.76$. This experiment shows that English auctions with buyout prices can indeed increase sellers' income, and the lower the buyout price, the easier it is to be accepted [18]. 
Mathews proposed that when a bidder is impatient to wait for the end of an English auction with a buyout price, the seller can increase his expected revenue by setting a relatively higher buyout price. Therefore, risk-seeking bidders are more willing to pay the additional fees included in the buyout price to end the auction as soon as possible [19]. Mathews and Katzman examined the impact of customers' risk preference in English auctions with buyout prices based on eBay's buy-it-now price system [20]. In 2006, Zoltan asserted three forms of buyout prices - fixed buyout price, a temporary buyout price, and permanent buyout price. $\mathrm{He}$ and his team discussed bidders' threshold price in online English auctions with permanent buyout prices and reserve prices, and proposed that the equilibrium value of the bidder's threshold price can be calculated by the utility function of bidders' valuation distribution, and the threshold price is between the reserve price and the buyout price [21].

From the perspective of modern economics, online auctions are mostly inconsistent with the setting of the traditional auction theory. Some current studies merely give predictive results from the traditional auction theory, which are extremely sensitive to hypothesis and factors, while other studies conducted in the recent years have cast doubt on former theories, and have proposed few feasible new theories.

\section{METHODOLOGY}

\subsection{Research Design}

While traditional art auctions require bidders to bid in a specific place at a specific time, online art auctions last for a relatively long time, generally weeks or even months. Theoretically, the longer the duration of an online auction, the more participants and the higher the profit of auctioneers. Nevertheless, in real-life situations, even when most websites have developed bidding agents for the convenience of bidders, auction duration that is excessively long would often cause customer loss and damage profits. Therefore, people combined traditional fixed-price selling with online art auctions and created a new type of modified online auction: online art auctions with buyout prices. In 1999, Yahoo! became the first auction site to use online art auctions with buyout prices. Nowadays, most sellers on online auction sites choose to use such auctions to sell works of art, such as Taobao, eBay, etc. Different types of buyout price auctions arose from different platforms. This research classifies those modified auctions into three main types: online art auctions with fixed, temporary, and permanent buyout prices, and builds a game model to analyze the optimal bidding strategies in each of them. A game model is considered to be an efficient way to analyze a game in the aspects of players, strategies, payoffs, and outcomes, thus being used in this research to study the bidding strategies in online art auctions as typical static games with incomplete information.

\subsection{Data Collection}

This research is conducted based on the independent private value model (IPV model) proposed by Vickery in 1961 for four common auction types (English auction, Dutch auction, first-price sealed-bid auction, and second-price sealed-bid auction). The IPV model is the cornerstone of the auction theory, which applies to the fundamental situation that the auction item has an independent private value to each bidder in the auction. Assuming there are bidder $\mathrm{i}$ and any other random bidder $\mathrm{j}$ in the auction, four classic hypotheses of the IPV model are as follows:

Hypothesis 1: Private Values. The valuation of bidder i is the private information of the maximum amount of money he is willing to pay for the auction item, and this value would not be affected whether other bidders know it or not.

Hypothesis 2: Independent types. Independent types mean that the valuation of bidder $i$ will not be affected by the valuation of bidder $\mathrm{j}$. Thus, even if bidder $\mathrm{i}$ knows bidder j's valuation, he will not alter his own valuation on the auction item.

Hypothesis 3: Symmetry. Valuation of all the bidders in the auction follows the same distribution.

Hypothesis 4: Risk neutrality. All bidders are risk-neutral, which indicates that each bidder will make every effort to maximize his expected utility.

The first three hypotheses describe the structural conditions confronted by bidders participating in the auction, while the fourth one focuses on the characteristics of bidders themselves. All the information described in the independent private value model belongs to common knowledge for both bidders and sellers. The following part will elaborate on why the independent private value model applies in modified online art auctions that this paper discusses and analyze the bidding strategies in these auctions.

\subsection{Data Analysis}

The IPV model applies to the circumstance in which everyone participating in the auction has a unique preference for specific items and will not change his preference due to others' preferences. Currently, diverse artworks of all kinds are at sale in online art auctions with buyout prices, and most artworks do not have a certain value, while the valuation of different people may be diametrically opposed on a single art piece. For instance, some handicrafts with unique styles are valued entirely by personal preferences. Therefore, this 
research paper assumes that online art auctions with buyout prices conform to the independent private value model, in which bidders' valuation of art auctioned are independent to each other. The value of artworks to each customer is different, and customers' valuation does not affect each other. Even if bidders observe other bidders' information about the values of the auction items, they will not develop a tendency to modify their bidding strategies, and bidding behaviors depend solely on their own valuation.

Under the conditions in the independent private value model discussed in the preceding part, this study builds a game model on online art auctions with buyout prices, which has the four following hypotheses:

Hypothesis 1: All bidders participating in the auction are rational and risk-neutral.

Hypothesis 2: Bidder i's valuation is $v_{i}, v_{i} \in[\bar{v}, \underline{v}]$. In the auction duration $[0, \mathrm{~T}], \mathrm{n}$ participators arrive randomly conforming to the Poisson distribution.

Hypothesis 3: The buyout price set by the seller is B, $B \in[\bar{v}, \underline{v}]$ and is the optimal price for the seller.

Hypothesis 4: There is a threshold value of valuation $\hat{v}$, $B<\hat{v}<\bar{v}$. If bidder i's valuation $v_{i} \geq \hat{v}$, he will choose the buyout option to win the auction item right away.

Based on the aforementioned hypotheses, the following study will analyze the optimal bidding strategies in online art auctions with fixed, temporary, and permanent buyout prices.

\subsubsection{Bidding Strategies in Online Art Auctions with Fixed Buyout Prices}

Due to their low time cost and convenience, online art auctions with fixed buyout prices are becoming the most common type of modified online auction applied on multiple platforms such as eBay and Taobao. Figure 2 is an example of the webpage in an online art auction with a fixed buyout price.
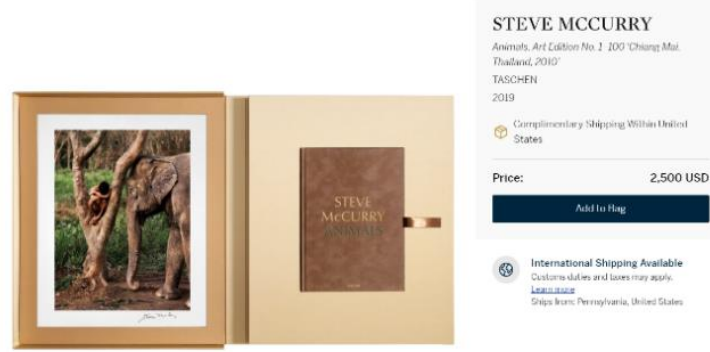

Figure 2. Contemporary art auctioned with a fixed buyout price on www.sothebys.com

There are two kinds of possible situations in this auction type: whether bidder i's valuation is higher or lower than the buyout price set by the seller.
(1) When bidder i's valuation is lower than the buyout price $\left(v_{i}<B\right)$, the optimal bidding strategy for him would be not to participate in the auctioning process, because if he wins the object with the buyout price, he would get a negative utility and be worse off. Thus, any rational bidder would not participate in the auctioning process in this case.

(2) When bidder i's valuation is higher than the buyout price $\left(v_{i}>B\right)$, he can whether choose the buyout option right away or wait until there are more bidders arriving. However, if bidder $\mathrm{i}$ hesitates, his probability of winning will drop aggressively as more people arrive, which means that his expected utility will be lower. Thus, bidder i's optimal strategy would be to win the object with the buyout option as soon as he arrives if his valuation is higher than the buyout price.

\subsubsection{Bidding Strategies in Online Art Auctions with Temporary Buyout Prices}

In online art auctions with temporary buyout prices, which are mainly applied on eBay, the first participant gets to choose whether to bid and turn the auction into a regular online English auction or to end the auction with the buyout price. The optimal bidding strategy alters when bidder i's valuation has different relationships with the buyout price.

(1) When bidder i's valuation is lower than the buyout price $\left(v_{i}<B\right)$, any rational bidder would not end the auction with the buyout price since that would cause the utility to be negative. Thus, the optimal strategy for bidder $\mathrm{i}$, in this case, would be to choose the bidding option as soon as he arrives and to only be willing to bid up to $v_{i}$ if necessary.

(2) When bidder i's valuation is higher than the buyout price $\left(v_{i}>B\right)$, he has the following two strategies:

(1) If bidder i's valuation is lower than the threshold value $\left(B<v_{i}<\hat{v}\right)$, he should choose the bidding option right away. However, he will bear the risk that the final price might be higher than the buyout price or even higher than his valuation.

(2) If bidder i's valuation is higher than the threshold value $\left(v_{i} \geq \hat{v}\right)$, he should choose the buyout option right away.

\subsubsection{Bidding Strategies in Online Art Auctions with Permanent Buyout Prices}

Online art auctions with permanent buyout prices are the most flexible among all three types of modified online art auctions, in which any bidder can end the auction with the buyout price while the price ascends. The final price would either be the buyout price or the highest bid during the auctioning process, which is 
definitely lower than the buyout price. Such auctions are applied at sites such as Yahoo! and Amazon. Bidder i's optimal strategies are also different when his valuation has different relationships with the buyout price.

(1) When bidder i's valuation is lower than the buyout price $\left(v_{i}<B\right)$, any rational bidder would not choose the buyout option since that would cause the utility to be negative. Thus, the optimal strategy for bidder $\mathrm{i}$, in this case, would be to choose the bidding option as soon as he arrives and to only be willing to bid up to $v_{i}$ if necessary.

(2) When bidder i's valuation is higher than the buyout price $\left(v_{i}>B\right)$, he has the following two strategies:

(1) If bidder i's valuation is lower than the threshold value $\left(B<v_{i}<\hat{v}\right)$, he should choose to bid. However, he will bear the risk of having a lower probability to win since any other random bidder with valuation higher than the buyout price could choose the buyout option.

(2) If bidder i's valuation is higher than the threshold value $\left(v_{i} \geq \hat{v}\right)$, he should choose the buyout option right away.

\section{RESULTS AND DISCUSSION}

In the research process, game model was built in order to study the optimal bidding strategies in online art auctions with different buyout prices in the research process. In conclusion, under the independent private value model, no matter which type of buyout price is adopted in an online art auction, the dominant strategy of bidders is early bidding (proxy bidding), which is to say a bidder should make his move immediately when he figures out his bidding strategy. Moreover, the research focuses separately on the optimal bidding strategy of each type of buyout price art auction by comparing bidder i's valuation and the buyout price. In online art auctions with fixed buyout prices, bidder $\mathrm{i}$ should not participate when his valuation is lower than the buyout price and should choose the buyout option as soon as possible when his valuation is higher than the buyout price. In online art auctions with temporary buyout prices, when bidder i's valuation is lower than the buyout price, bidding would be the optimal strategy. When his valuation is higher than the buyout price and lower than the threshold value, he should choose the bidding option. When his valuation exceeds the threshold value, he should choose the buyout option right away. In online art actions with permanent buyout prices, bidder i should choose to bid when his valuation is lower than the buyout price. When his valuation is higher than the buyout price, he should choose to bid if his valuation does not exceed the threshold value and to end the auction with the buyout price without hesitation if his valuation exceeds the threshold value. To measure his bidding strategies, a bidder must consider thoroughly on the risk of each move and the benefit that could be gained. The optimal strategy of a bidder does not change his purchasing power or valuation, but only strikes a balance between his probability of winning and expected utility if winning, and thus enables him to allocate his resources in the most efficient way.

\section{CONCLUSION}

As online art auctions are booming while related studies are deficient, this research focused on the optimal bidding strategies in online art auctions with different buyout prices. To begin with, this paper attained a systematic recognition of such auctions by reviewing preceding studies on the auction theory, bidding strategies in online auctions and modified online auctions. Then, based on the independent private value model which would apply in art auctions, this paper constructed a game model for online art auctions with different buyout prices and analyzed the optimal bidding strategy with each type of buyout price, reaching the conclusion that a bidder has a dominant strategy of early bidding no matter which type of buyout price is applied. In different types of buyout price auctions, he should compare his valuation with the buyout price to determine his further move, leading to the final strategy of leaving, bidding, or ending the auction with the buyout price. This paper is innovative for the fact that it offers bidders in online art auctions with buyout prices the specific method to figure out the optimal bidding strategy and proposes a threshold value to make bidders better understand whether to choose the bidding option or the buyout option according to their own valuation. The deficiency of this paper is that it is conducted mostly on hypothetical conditions, which is too idealistic to capture the trend of the ever-changing online art auction market. There are still many potential factors affecting bidders' bidding strategy in real-life online art auctions. Plus, all the analysis in the model is based on an appropriate buyout price, while in reality there are numerous problems with setting up buyout prices. Buyout prices that are too high defeat the original purpose, while low ones are likely to damage profits, in either way negatively affecting market efficiency and causing bidders to develop different mechanisms that this research does not apply to. In future researches, more data and factors can be introduced to make theoretical models more consistent with real-life circumstances in all aspects, so as to draw conclusions that are more accurate and empirical.

\section{REFERENCES}

[1] S. Gupta and J. Gallien, Temporary and permanent buyout prices in online auctions, Working Paper, 2005

[2] E. B. Budish and L. N. Takeyama, Buy prices in 
online auctions: Irrationality on the Internet? Economics Letters 72, 2001, 325-333.

[3] Yan, Guan. China Auction Industry Report 2017. China Association of Auctioneers www.caa123.org, 2018.

[4] Friedman L. A competitive bidding strategy[J]. Operations Research, 1956, 4(1), 104-112.

[5] Vickrey W. Counter speculation, Auctions, and Competitive Sealed Tenders[J]. Journal of Finance, 1961, 16(1): 837.

[6] Vickrey, William. Auction and Bidding Games in Recent Advances in Game Theory[C]. New Jersey: The Princeton University Conference. Princeton, $1962,1527$.

[7] Kremer 1. Information aggregation in common value auctions [R]. Northwestern University, Evanston, I L. 1999.

[8] Bali V, Jackson M. Asymptotic revenue equivalence in auctions [J]. Journal of Economic Theory, 2002, 106: 161-176.

[9] Leszczyc P P. The psychology of auctions: Enriching models of bidder and seller behavior [J]. Advances in Consumer Research, 2004, 31 (1): 90-93.

[10] Milgrom P R, Weber R J.A theory of auctions and competitive bidding [J]. Econometrical, 1982(50): 1089-1112.

[11] WILCOX R T. Experts and amateurs: The role of experience in Internet auctions [J]. Marketing Letters, 2000, 11: 363-374.

[12] Engelbrecht-Wiggans R. Empirical Contributions to the theory of Auctions or Why Do Real Bidders Bid the Way they Do? Notes prepared for the TOW conference on applied research. Concerning auctions and mechanism design, 2000.

[13] BAPNA R, GOES P, GUPTA A. A theoretical and empirical investigation of multi-item online auctions [J]. Information Technology and Management, 2000, 1 (1): 1-23.

[14] Ward S G, Clark J M. Bidding behavior in online auctions: An examination of the eBay Pokemon card market $[\mathrm{J}]$. International Journal of Electronic Commerce. 2002, 6(4): 139-155.

[15] Lucking-Reiley D.. Auction theory: what's being auctioned and how $[\mathrm{J}]$. The Journal of industrial economics, 2000, 48(3): 227-252

[16] Wang X., Montgomery A., Srinivasan K., When Auction Meets Fixed Price: A Theoretical and Empirical Examination of Buy-it-Now. mimeo, Carnegie Mellon University. 2004.

[17] Caldentey R., Vulcano G. Online Auction and List Price Revenue Management [C]. Stern school of Business, New York University, 2004.

[18] Durham Y., Roelofs M., S.Standifird. eBay's Buy-lt-Now Function: Who, When and How, Topics in Economic Analysis and Policy, 2004, 4: $1-22$.

[19] Mathews T. A risk averse seller in a continuous time auction with a buyout option. Brazilian. Electronic Journal of Economics. 2003, 5 (2)

[20] Mathews T. The Impact of Discounting on an Auction with a Buyout option: a Theoretical Analysis Motivated by eBay's Buy-It-Now Feature. Journal of economics. 2004. 81(1): 25-52.

[21] Zoltan Hidvegia, Wenli Wang and Andrew B. Whinstion. Buy-price auction [J]. English Journal of Economic Theory. 2006: No. 129. 